\title{
Boundary (Re-)Constructions as Human-Nonhuman Intra-Actions Within the Workplace
}

\author{
W. David Holford \\ University of Quebec at Montreal
}

This paper proposes the concept of boundary (re-)constructions. An initial framework depicts subjects shaping objects across enactment phenomena just as, conversely, objects shape subjects' interpretations and experiences. The following case study presentation highlights the residual duality still residing within this initial framework. Onto-epistemological insights involving hybridized categories and socio-material entanglement allow us to subsequently reframe boundary (re-) constructions as intra-actions (as opposed to inter-actions) between humans and objects. Effective knowledge sharing involves productive intra-actions, which, in turn, requires relational engagement between intra-acting members. Such engagement requires management's implication towards ensuring a psychological safety net within the workplace.

\section{INTRODUCTION}

Boundary objects have long been associated with communities of practice. In principle, these objects are mediums which help transmit differing perspectives (i.e. knowledge sharing) between interacting members. The term 'boundary' implies that such objects lie at the social intersection between two or more inter-acting members. Past research often enquired into the relative effectiveness of boundary objects, and as such, has often proposed 'key' object characteristics. For the manager-practitioner, this meant focusing on tangible technical/physical attributes. This paper, on the other hand, argues for a shift in emphasis towards more intangible human/subjective factors at play. Along with this increased emphasis, comes an increased responsibility on both management and members in regards to their respective behaviors and attitudes. Towards this end, our basic assumptions of what we think boundary objects are (i.e. questions of ontology, or theory of being) and how we go about making sense of them (i.e. questions of epistemology, or theory of knowledge) will be brought into question.

In the following paper, we first review past epistemological and ontological positions within the literature on boundary objects, and how on occasion these have perhaps misled us towards identifying tautological prescriptions for 'effective boundary object' conditions which fail to place sufficient emphasis on human-object interaction dynamics. This is followed by alternative cognitive, epistemological and ontological threads which allow us to shift our level of analysis towards first asking ourselves what critical enabling conditions allow for effective knowledge 
sharing via boundary object/human interaction. Based on this alternative view, the concept (or framework) of boundary constructions is proposed. A short case study attempts to validate how this may be integrated within dialogical interactions between individuals. Our results, while supporting the notion of boundary constructions, suggest that humans and objects not only interact, but intra-act, thus eliminating any remaining vestiges of the object-subject duality within our initial framework. This intra-action is consistent with Orlikowski's (2007) sociomaterial entanglement or Barad's (2007) agential realism. Finally, we propose specific managerial practices which may help towards enabling effective boundary constructions within the workplace.

\section{LITERATURE REVIEW}

Star and Griesemer's (1989) much cited account of how the Museum of Vertebrate Zoology at the University of California was built, speak of boundary objects as "things" which coordinate the perspectives as well as serve the information needs of the intersecting social worlds of various actors towards a given purpose. In addition, "boundary objects are objects which are both plastic enough to adapt to local needs and the constraints of the several parties employing them, yet robust enough to maintain a common identity across sites... These objects may be abstract or concrete...The creation and management of boundary objects is a key process in developing and maintaining coherence across intersecting social worlds." (1989, p.393)

According to the authors (1989, p.410-411), there are four categories of boundary objects: 1) repositories (e.g. databases or libraries) of objects "indexed in a standardized fashion" which individuals can borrow for their own purposes without the need for negotiation; 2) ideal types which are locally adaptable due to their vagueness since they do not "accurately describe the details of any one locality or thing"; 3) standardized forms which emphasize methods of common communication over long distances (and are therefore especially applicable to dispersed work groups); and 4) coincident boundaries which have different internal contents depending on the interests and perspectives of each party yet are still common objects with the same boundaries.

From an ontological viewpoint, Star and Griesemer's (1989) concepts of boundary objects lead to varying degrees of duality between the object and subject. For example, repositories imply that while on the one hand the individual who interacts with these will use a certain degree of subjective interpretation, it is assumed, especially within the field of information technology, that such subjective interpretation is minimized (or in other words, a 'distant objective' viewpoint is attained) across the use of codified knowledge. As for ideal types and coincident boundaries, there is an explicit acceptance that the subject's active interpretation and viewpoint that comes into play, yet the object is still viewed as being discretely and permanently separate from the subject. Here, the object can be seen as either being static, or as a changing entity in which we focus only on its static end-result. Later interpretations of boundary objects in certain literature have continued to imply varying degrees of permanent separation between the actor-individual and the object: "boundary objects are artifacts, documents, terms, concepts and other forms of reification around which communities of practice can organize their interconnections" (Wenger, 1998, p.107); or "boundary objects are physical objects that enable to understand other perspectives" (Feldman et al., 2006, p.95).

Although Bødker (1998) acknowledges the mediation that occurs around most of these 'objects', they are nevertheless viewed as static representations. This epistemological subtlety is 
perhaps best summarized by Lutters (2001) who highlights Fahey and Prusak's (1998) "critique of the conceptual foundations for most knowledge management projects", and most notably, the emphasis made on "knowledge stock to the detriment of knowledge flow", whereby the "boundary object concept only partially addresses this critique", since "it still suffers from an artifact-centric view of knowledge, rather than [being] a process oriented perspective" (2001, p.35-36).

Some researchers have proposed that effective boundary objects are tangible, up-to-date, easily accessible, (Carlile, 1997) and concrete (Bechky, 2003). Carlile (2002) identifies three factors for generating useful boundary objects: 1) the boundary object needs to provide a common language for actors to represent their knowledge; 2) the boundary object must provide a means for actors to express different interpretations, thereby allowing the possibility for novelty to emerge; and 3) the boundary object must facilitate processes by allowing the actors to change its contents in order for it to continue to be useful to all involved participants. But Carlile's level of analysis tends to imply boundary objects as being independent variables to the subject-actor, while simultaneously implying the subject-actor to be dependent on the boundary object. In the following sub-section we will draw certain cognitive and epistemological insights from authors such as Glasersfeld (2002) and Weick (1995 and 2009) on the nature and relationship of the subject and his environment. This, in turn, will allow us to shift more emphasis on the active and dynamic role the actor has over objects, and thereby attempt to shift our focus as to where and what the most pertinent 'success factors' are when speaking of effective 'boundary objects'.

\section{The Mutual Shaping of the Subject and Object: Enter Boundary (Re-)Constructions}

Glasersfeld's (2002) argument for a radical constructivism makes us re-question the representational notion of a pre-existent environment (as a collection of pre-existing objects) that is simply there to be discovered by an objective and separate observer. There are two issues to consider here: one is the notion of an objective and separate observer and the other is that of a pre-determined reality. Glasersfeld (2002) directly addresses the claim of observer objectivity by first explaining, across Jean Piaget's work on cognitive development, how human mental operations lead up towards a mental/subjective construction of reality. These operations involve both the construction of action and symbolic schemes (the latter being mostly linguistic in nature, based on interpretive semantic rather than arbitrary semiotic analysis) leading towards sensorimotor and conceptual knowledge, respectively (2002, p.76). Each of these schemes is constructed on the basis of personal (and therefore unique) experiences which may be more or less similar, but never identical to, another person's constructions; or as Glasersfeld (2002, p.158) states: "whenever we interpret what others say, or the way they act, we interpret what we hear or see in terms of elements that are part of our own experience. We cannot have another's experience." Furthermore, by illustrating Piaget's conception of mental schemes as being inherent processes of assimilation and accommodation coupled with learning feedback mechanisms (the latter being very similar to cybernetic systems of negative feedback), Glasersfeld (2002, p.155-156) explains how "vital [human] knowledge is constituted by [personal] rules that indicate which particular actions are successful in eliminating particular [system] perturbations. No knowledge of an independent external reality is gained, nor is any such knowledge needed." Here, inductive learning from experimental outcomes is attained by experimenting and constructing "a repertoire of schemes" that enables one to maintain his or her "sensory perceptions within an acceptable range of reference values." The key point is that humans (or any other living organisms) learn by constructing a viable (as opposed to a 'true' in 
the positivistic sense) picture of reality; and that we may occasionally "bump" into our external reality across "failures" (2002, p.156). This rejoins Weick's (1995) theory of individual and organizational sensemaking, whereby sensemaking, being the human "invention that precedes interpretation" (1995, p.14), involves: a) on-going updating (again in a cybernetic-like fashion of negative feedback) initiated by environmental disturbances, and b) drives towards plausibility as opposed to what is true in the absolute sense. In other words, "truth is what works" (James, 1907) in that our external reality is much too complex to comprehend in terms of exact correspondence. As Glasersfeld (2002, p.156) explains, "the idea of correspondence with reality is replaced with the idea of fit. Knowledge is good knowledge if it fits within the constraints of experiential reality and does not collide with them. This fit must be attained not only insofar as a cognitive structure, a scheme, a theory, have to remain viable in the face of new experience or experiments, but also in that they prove compatible with other schemes and theories one is using." Hence, "the requirement that knowledge be called true knowledge only if it reflects the real world, is relinquished for the requirement that is be found conducive to the attainment of our goals in the world as we experience it" (2002, p.44).

So far, we have argued that the observer can no longer be viewed as being separate and objective. The observer's unique (and therefore subjective) interpretative schemes influence or shape his/her experiences. And up to this point, there is really nothing that counters Carlile's (2002) position of the subject-actor being dependent on the boundary object via his/her interpretation of it. More recent literature by Lee (2007) on boundary negotiating artifacts, discusses in more detail how artifacts can help mediate/negotiate new shared meanings as contexts change. But Weick (1979 and 1995) goes one-step further by highlighting the subjectactor's own influence on (and shaping of) the object by reiterating Berger and Luckmann's (1966) construction of social reality across the process of enactment through which we proactively shape and structure our realities in an unconscious manner. And in this sense, we can now firmly argue against a static pre-existent environment. Morgan (1997, p.141) offers a succinct explanation on enactment: "Although we often see ourselves as living in a reality with objective characteristics, life actually demands much more of us than this. It requires that we take an active role in bringing our realities into being through various interpretive schemes, even though these realities may then have a habit of imposing themselves on us as "the way things are"" (Morgan, 1997, p.141). Weick (2009, p.190) cites Follett (1924) to describe the truly two way shaping process that occurs between the environment (in the most general sense) and the subject:

"...the activity of the individual is only in a certain sense caused by the stimulus of the situation because that activity is itself helping to produce the situation which causes the activity of the individual...My farmer neighbours know this: we prune and graft and fertilize certain trees, and as our behaviour becomes increasingly that of behaviour towards apple-bearing trees, these become increasingly apple-bearing trees. The tree releases energy in me and I in it; it makes me think and plan and work, and I make it edible fruit. It is a process of freeing on both sides. And this is a creating process." (Follett, 1924, p.118-119).

Therefore, as an engaged subject, we have a creative role (and therefore, partial accountability) in shaping our environment. No longer can we hide behind the illusionary mask of 'pure' objectivity: "Objectivity is a subject's delusion that observing can be done without him. 
Invoking objectivity is abrogating responsibility - hence its popularity" (Glasersfeld 2002, p.149). Of course, this enactment process can be either constructive or deleterious in nature. We can choose to enact (or 're-create') different environments including the purely destructive, the status-quo (whether destructive or constructive in outcome), or a refreshing and much-needed change (Weick, 1979 and 1995).

Returning to boundary objects, we can now propose that they are shaped by actor-subjects (via enactment), just as they also shape actor-subjects (via the subject's interpretative schemes). Furthermore, this occurs in a dynamic and continuous manner. Hence, we propose boundary (re)constructions as an alternative term to boundary objects. It is important to note that this puts heavy emphasis on the process aspect of the term 'construction' as opposed to its end-resultant and static aspect of 'construct'. We can now reword the factors identified by Carlile (2002) for effective boundary objects as follows: 1) the actors must provide a common language for them to effectively represent their respective knowledge across the help of a co-constructed or conegotiated boundary construction; 2) the actors must provide a means to express their different interpretations across the help of a co-negotiated boundary construction; and 3) the actors must continually co-negotiate and co-transform the boundary construction so as to maintain an ongoing pertinence to all involved participants.

\section{FIGURE 1 \\ DIALECTICAL UNDERSTANDING TOWARDS EFFECTIVE KNOWLEDGE SHARING}

\section{Enabling Conditions}

\section{Towards Productive}

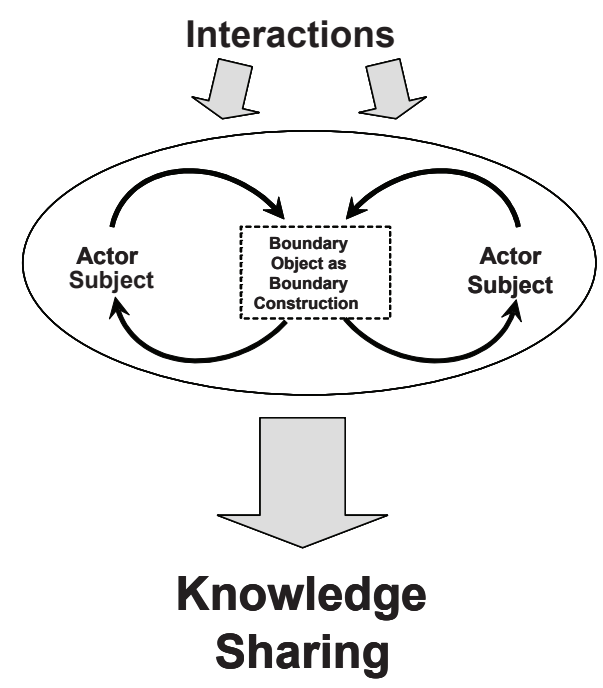

This re-wording, for one, highlights the dialectical shaping interaction occurring between coactors and objects. But how can one ensure a "productive" interaction as implied in the above rewording? Here, we borrow the term from Tsoukas $(2009$, p.13) in his reference to "productive dialogue": i.e. "productive" in the sense of participants taking a "distance from their customary 
and unreflective ways of understanding and acting, and reconceptualize a situation at hand through conceptual combination, expansion and/or reframing." For this to happen, Tsoukas (2009) speaks of the need for a relational engagement to occur between interacting parties. Along similar lines, Schober (1996, p.142) explains, "communication is unsuccessful when neither party manages to mentally 'step into the other's shoes', to be non-ego-centric". Taking in the other's point of view, as Mead (1934) explained, involves taking the attitude of the other and of being fully human by maintaining an inner conversation with a generalised other. But what induces parties to embark upon this relational engagement? Our (research) question thus becomes, 'Which enabling condition(s) encourage productive interactions (in itself involving relational engagements) between co-actors and a boundary construction leading towards effective knowledge sharing?' Figure 1 illustrates both our proposed dialectical framework and its associated research question. Not only is there a first order shift towards accountable actions and thoughts between interacting actors (as enactors), but also a second order shift towards management's responsibility of enacting the enactors by instilling effective enabling conditions.

\section{METHODOLOGY}

The research site, given the pseudonym, NorAm Aircraft Engines, is an aircraft engine manufacturer which employs over 9000 people world-wide. Preliminary discussions with a first workgroup (the Engine Operability Development or EOD group) not only confirmed their interest to participate in the study, but were involved in bi-weekly meetings with another group that had not been initially identified (the Engine Component Rig Testing or ECRT group). This second group was also approached and subsequently accepted to participate.

\section{The EOD and ECRT Workgroups}

The EOD group is responsible for ensuring the development of adequate engine operability envelopes throughout all phases of engine development programs. The proper establishment of the engine operability envelope is of critical importance, in that it delimits the boundaries beyond which the aircraft risks running into critical compressor surges or other types of catastrophic engine failures. EOD group members have a good general understanding of the various engineering disciplines involved in engine design and development. The group consists of 5 male engineers, with 7-25 years experience. All have had prior experiences in either one or more engineering specialty fields such as dynamics, aerodynamics, design and/or general project engineering. A principal objective of the EOD group is to ensure that meaningful engine component test data is generated. Establishing the type of engine test data to be generated is negotiated between the EOD group, the various engineering specialty groups, and the ECRT group; the latter being responsible for the actual generating and integrity of the required engine component test data. In turn, the ECTR group consists of 7 male members. Their responsibilities include the development and preparation of component test rigs (required for each new engine development program), their subsequent test runs, and the proper collection of the test data. The ECTR group consists of one relatively young aerodynamics engineer ( 2 years prior experience in aero-design), one mechanical engineer with 10 years experience in engine rig design work, and 5 aero-mechanical technicians with 15-25 years experience in coordinating and running the various types of test rigs. Both groups interact with each other daily (informal) and also meet bi-weekly on a formal basis. 


\section{Data Collection}

The interactions (primarily as dialogue), within, as well as between, the two specific work groups at the NorAm Aircraft Engines Company was used as a case study (Cresswell, 1998, p.61; Yin 2003; Eisenhardt 1989). Our aim was to both "test/build theory" as well as to "provide description" (Eisenhardt, 1989, p.535). Within this perspective, it was especially important to be vigilant for 'emergent' dimensions, categories or alternative theory. Here, we can find specific inspiration across Schwartzmann's (1993, p.47-72) ethnographic studies in organisations involving a dialogical inductive-deductive process between empirical evidence and theoretical elaboration across thick descriptive writing. Hence, for the purpose of our work an ethnographic case study approach was adopted using direct (non-participant) observations. This was conducted over a three month period in early 2007. These observations were also coupled with one-on-one ad hoc conversations/informal interviews, whereby the former often melded into the latter, and vice-versa, in dialectical fashion. This overall informal approach was also complemented by more formal semi-directed interviews towards the end of our 3 month stay.

Although case studies and ethnography can often be viewed as distinct approaches (Cresswell, 1998, p.58-65), they are also seen to often overlap one another (Cresswell, 1998, p.66). While ethnography is typically reserved for larger cultural systems, and case studies to bounded (and typically smaller) systems or "units" (Cresswell, 1998, p.66), the synthesis of the two approaches has often been adopted across ethnographic case studies (for example, Prosser (1995) in his multi-site study on the process of child abuse investigations in the UK, etc.) and has most recently been justified by Beaulieu, Scharnhorst and Wouters (2007) as a methodology which synthesizes the more bounded case-type research investigation with the more open-ended ethnographic approach.

The epistemological stance adopted in this study echoes Rosaldo's (1989, p.178-179) argument in that objectivity as scientific "neutrality and impartiality" is laced with subjective dimensions. That is not to say that Rosaldo refutes the etic side, but rather is warning us of falling under its illusions of impartiality. We make the argument for adhering on the one hand to a 'refreshed' etic - that is, one that acknowledges and exploits the observer's subjective interpretations, emotions, opinions, etc. On the other hand, we also acknowledge the importance of obtaining the observed or indigenous point of view. Hence, we adhere to Cuche's (2004, p.115) argument that as a methodological principal, both cultural relativism and ethnocentrism be used in a complementary fashion to allow the researcher to apprehend the dialectic of "the same/self and the other, the identity and the difference...which is the foundation of social dynamics". The etic, while never containing 'absolute truth', nor being impartial, may contain certain local small and partial 'truths' (Whitehead, 1954) generated from the 'outsiders point of view' that may not be visible to the 'indigenous point of view'. Conversely, while it is true that acknowledging and trying to credit the indigenous point of view is a key dimension in understanding a contextual 'reality', one can never be totally emic - as outside observers trying to pursue an emic ethnography we will always at one point or another conduct some interpretation that implicitly uses our own personal values, beliefs and experiences coming from the 'outside'. But by acknowledging the etic within us as investigators, while simultaneously pursuing the emic, we place ourselves in a better position to recognize the limitations of both, while also trying to profit from their combined strengths.

Three embedded units of analysis within the single case study were chosen, namely: 1) the bi-weekly inter-group meetings between EOD and ECRT; 2) the EOD group; 3) the ECRT group. For this paper, we limited ourselves mostly to the first unit of analysis. 
Note-taking in front of participants was gradually increased over the $1^{\text {st }}$ week subsequent to explicitly asking the participants for their permission to do so. The taking of digital recordings was initially avoided, and in fact, was not originally intended to be used during the more informal data gathering stage of this study. But the virtually impossible task of noting down verbatim, body 'language' and voice tonalities at the same time soon made me entertain its possibility. In fact, the relatively quick on-set of sympathy at seeing me struggle in taking down notes during the rapid yet very rich bi-weekly morning meetings gave me the 'courage' to ask the question; which to my pleasant surprise was an unhesitating "yes, why not" response by all, along with some good-natured ribbing such as "this is going to cost you" or "ya, well now we'll all have to behave and watch what we say". The digital recorder could be turned off at any time by anyone, and soon became an 'expected presence' within the meeting room - and was occasionally, along with myself, the subject of good-natured teasing.

Observations were conducted while trying to remember Spradley's (1980) recommendations of: 1) being constantly vigilant to all that is done, said and occurs so as to minimise the bias of selective inattention; 2) using a 'large angled lens', whereby the observer must at all times try to capture the widest spectrum of information possible.

The primary design criterion for this research was based on the constructivist measure of trustworthiness as defined by Lincoln and Guba (1985), which involves the ability to generate empirically grounded theory or findings that are:

(1) Credible - findings and interpretations generated across: a) prolonged and persistent observations (so as to attain 'saturation' whereby events started to repeat themselves without having 'anything new' to add); and b) triangulation across the use of more than one method of data collection (in our case, observations and semi-directed interviews) so as to obtain the complementary perspectives of what people say vs what people do (Schwartzman 1993) (as opposed to triangulation in the strictly positivistic sense which involve the 'intersections' of findings);

(2) Transferable - findings that can be transferred to other settings or contexts across the use of detailed field accounts or 'thick description' (Geertz, 1998).

Also in support of this primary criterion of trustworthiness, was our desire to attain reliability of data by ensuring that the research was conducted "as if someone were looking over our shoulder" (Yin 2003, p.38); that is, making sure we had rigorous documentation of data (from observations and interviews) so as to provide an adequate audit trail. For observations, we drew upon Spradley (1980, p.63-84) who recommends: 1) the use of short in vivo condensed notes, which were often complemented with on-site in vivo digital recordings; 2) to be subsequently expanded within 24 hours or, as soon as possible, in a separate journal; 3) a reflexive journal on personal emotions and reactions in regards to recorded experiences; and 4) analytical notes that consisted of interpretations on what was observed, as well as questions or further points that needed to be verified.

Certain repeatable descriptive observations within the meeting room environment were complemented with short film recordings of various typical body movements (hand/arm movement, sketching/drawing/writing, etc.) which accompanied the verbal dialogue and interactions between the observed participants relative to the use of what the literature refers to as "boundary objects" (which we propose to redefine as boundary constructions). This was only conducted towards the final month of investigation, whereby a great deal of trust had been 
achieved between the researcher and the participating members within both workgroups.

\section{Data Analysis and Main Research Steps}

Descriptive data from observations and interviews were manually analysed and interpreted in a separate journal as per Spradley (1980): 1) against a priori concepts of our initial framework; and 2) for emerging categories which came about through repeated identification of comments, practices or any other type of observation. The nature of the data that was collected (digital recordings, hand-written observations and films) allowed us to analyse for verbal and non-verbal cues (voice tonality, facial expressions, body language, etc.) thus bringing forth important contextual information.

The following is a summary of the main research steps involved in this study within a format inspired by Schwartzman (1993):

Entry into the field and specific units of analysis made available a priori - this involves a certain degree of immersion and discovery of the field across observations and first contacts with the participants.

Gradual familiarisation with certain specialised terms used in each of the specific units of analysis studied; description of observations become more methodical in regards to the contextual activities and comments of the participants.

A first analysis: certain phenomena (whether known or novel), as a result of repeat occurrences, are retained; further readings ensue as a function of the familiarity, or lack of, in regards to the phenomena repeatedly observed

A second analysis: under what conditions do the phenomena repeat themselves? What are their implications?

Progressive building of framework: this involves a mix of revalidating certain a priori concepts, the abandonment of others, and the addition and re-integration of new categories.

Progressive redundancy of observations indicates saturation.

\section{RESULTS}

\section{The Bi-Weekly Inter-Group Meetings}

The first and lasting impression upon assisting the bi-weekly inter-group meetings between EOD and ECRT was the high degree of camaraderie found within each group as well as between both groups; and also extended between the two group managers (Gerry and Frank). Members, upon entering the meeting room a few minutes early, would often discuss non-work related topics (hockey, renovations, car repairs, etc.). Such socializing also involved a fair degree of good-natured cajoling. On other occasions, members, prior to the start of the meeting, often discussed specific technical issues related to joint project activities. This was often accompanied by the act of sketching a particular view of a rig or engine component that one member was trying to describe, justify or clarify. Throughout such conversations sketches were often drawn and modified in successive superimposing steps by each of the interacting members before finally converging towards a mutually agreed version.

Similar types of exchanges were also observed with the aid of pre-existing 2D drawings. Here, existing blueprints were modified (with superimposed dialogue) with pen/pencil to either express or explain one's own existing perspective (sensegiving), comprehend someone else's 
perspective (perspective-taking) or construct new perspectives (perspective-making). Once the formal meeting began, the EOD manager (Gerry) usually started by verbally calling out the first item on his agenda/status sheet. This sheet consisted of one or two-line descriptions identifying the development engine model/test rig combination in question, the principle tasks being monitored, a completion target date for each of these tasks, and the current status of the task in question. Most of the members had a copy of this same status sheet. Gerry's kick-off words of "QA510 Gas Generator?" would prompt a response by one of the attending members with words such as "We've finish-machined and installed the second compressor stator and the rotating bullet is now being installed. The gas gen. rig should be ready for first shake-down by the middle of next week." Gerry, as well as other members around the table would then note down on their status list, in relation to what had just been said. Gerry would then either go onto the next engine model/test rig on his list, or ask a further clarifying question such as:

Gerry: "Are we clear as to what tests Colin needs...do we know which running conditions, and which points we need to measure?"

Jon (from the ECRT group): "I spoke to Vincent about this last week, and told him we needed to do some measurements two degrees above and two degrees below the nominal..."

Gerry (in a patient tone, starts to provide sensegiving): "Ya, but that's another thing. What I'm talking about here is for the same (strong emphasis made on this word) operating point (pauses), in pressure ratio and in corrected speed..."

Jon (provides a cue that he's following Gerry's explanation i.e. perspective-taking): "Ya..."

Gerry (continues with sense-giving): “...and then recording the stabilization time needed for the outlet temperature to reach the ambient temperature."

Jon (major learning moment - self-discredits or modifies his own current assumptions): “Ah ok! I had understood it was...I'd better get back to Vincent on this - it sounds like I'm going to be a day late after all."

This prompted Gerry, and other members also involved with the item of concern to further modify their respective status lists. Each wrote something similar, yet different enough to address their own respective perspectives.

Whether during the formal meeting or after having reached the final item on the agenda/status list, members discussed a variety of technical issues they were jointly working on. As in the pre-meeting informal discussions, these conversations were accompanied by either active sketching from scratch or modification of existing drawings. A vivid detailed example (March $\left.12^{\text {th }}, 2007\right)$ involved Frank going up to the drawing board to draw and (simultaneously) verbally articulate a new test rig arrangement which he proposes should be tried out:

Frank: "Ya, because I think the problem...is that we've never run an engine rig with a plenum (gas containing chamber) like this" 
Frank simultaneously draws the following schematic of a plenum:

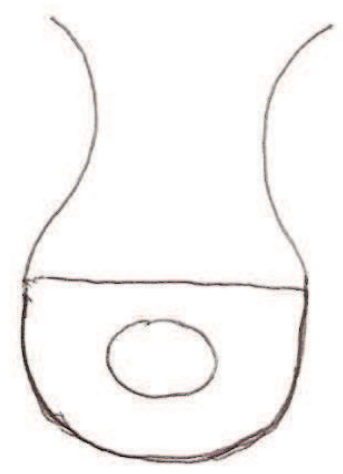

Frank then erases the two top extending lines, and adds a "+" and "-" sign in brackets so that it now looks as follows while at the same time saying:

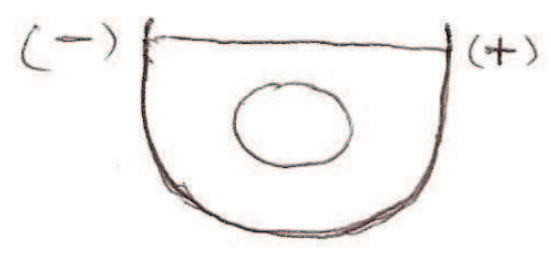

Frank: "Ok so this is how it's configured with the large nozzle. We actually used this set-up back on the QA700...the 700 family; it worked on the 706. They ran the engine on a rig test."

Mark: "the 706 or $705 \ldots$ "..

Frank: "Ya..."

Mark (agrees but also clarifies Frank's narration while pointing to Frank's sketch): “There wasn't a real nozzle so to speak...it was really configured like this."

Frank: "Ya, and they realized that there was some sort of static pressure variation; something low like right over here (points to - sign) and a high point over there (points to + sign).

Frank now draws an additional lower vertical line to the drawing as he says:

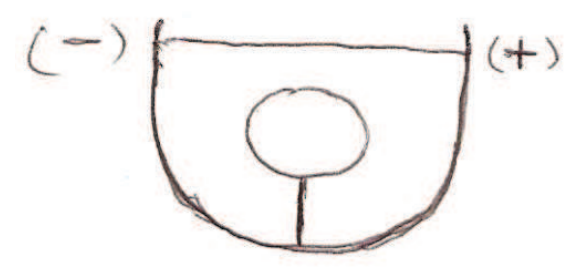


Frank: "They added a baffle, 'Bing!' (onomatopoeia) like this which really improved things. We didn't go into the intake...the solution was really in the compressor rig - the data showed this. I think it was because of this engine's IGV (inlet guide vanes)."

Frank, on his last sentence, simultaneously draws guide vanes on the existing sketch:

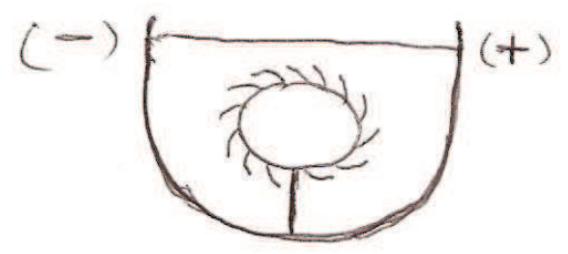

Frank: "We created this pre-swirl'..."

Frank then adds gas flow lines to his sketch and simultaneously says:

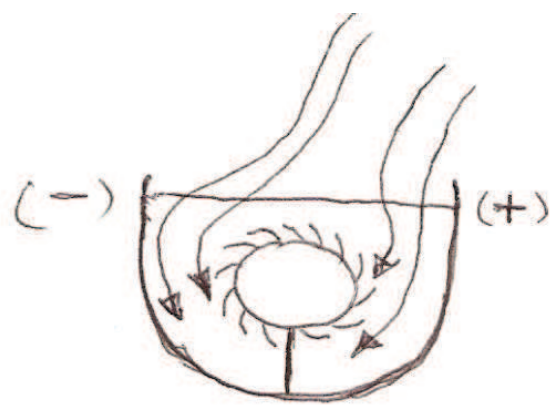

Frank: "The air comes in like this, and instead of descending equally on each side, it takes on this tendency more or less like this ..."

Mark (agrees with Frank's assessment): "Yep, that's what it does in reality."

Frank (acknowledges Mark's approval): “That's it, eh? (then points to lower vertical line representing the baffle) By closing off this area here, things improved a lot..."

Mark (again agrees with Frank): "Ya things got better when we did that..." Frank then points to the top left hand corner of the 'plenum' and adds:

Frank: "But we still have a problem on this side (then points to left side of vertical baffle) because of a dead zone. And that's where the temperatures got way high over here (then points to top right hand corner of baffle) and real low over here...I figure..."

Frank then draws a thick vertical line in the top half of the baffle and then says: 


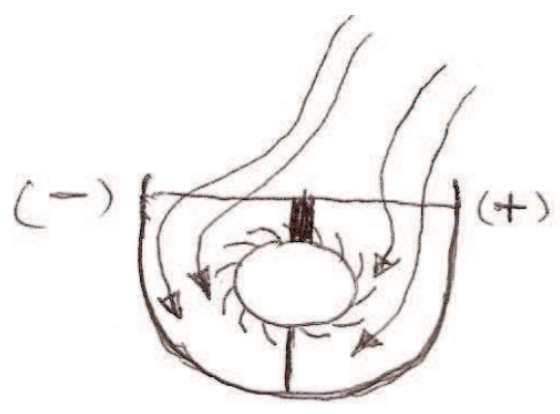

Frank: “...I figure, why not put a baffle right over here as well? This way we split the plenum in two zones..."

Frank then adds more gas flow lines to equilibrate the flux lines on both the left and right side of the baffle and simultaneously says:

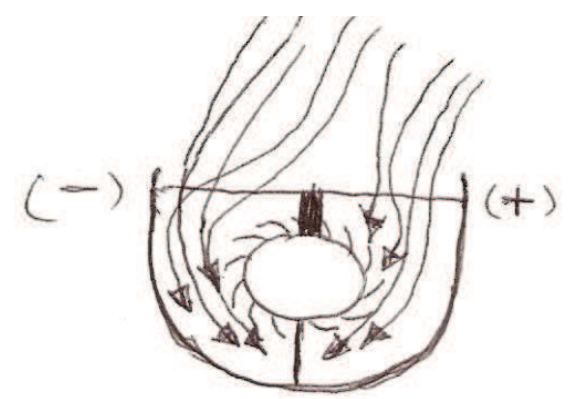

What is important to note in the above example is that it wasn't just the final resultant sketch that aided in the comprehension of Frank's perspective, but the step by step or incremental progression - of both verbal and visual aspects of an evolving story, almost like a film or 'cartoon'. Complementing the actual action of drawing is the frequent use of hand/arm movement to explain a particular aspect of the gas plenum arrangement.

In a more general sense, members often brought up new points of views which were accompanied by the active listening of others; but once expressed, responses were quick to follow, ranging from further questioning prior to acceptance or to further counter-argumentation. Such new points of views were often altered, modified or dropped altogether - yet counterarguments also went through the same process, often in parallel to the initial argument's transformation. All of this was typically conducted in an atmosphere of mutual respect, trust and appreciation of each others' contributions. Furthermore, sense-giving conducted by various members, including both managers, was principally to guide rather than to coerce. Initial sensegiving by one member was often 'self-discredited' (in the weickian sense) as a result of another member's counterpoint or questioning. Hence, 'healthy doubt' as defined by Weick (2001) was often present, and helped ensure a reasonable balance between the "crediting" and "discrediting" of beliefs and assumptions.

\section{A Forum for Healing Temporary Strains}

The above description is the predominant picture which emerged from aggregate observations as well as individual interviews within both the ECTR and EOD groups. Two separate events involving temporary strains between specific members between the two groups allowed us to take a glimpse of what would happen if mutual trust and respect were not present. 
The first event involved one member of the EOD group (Michael) who was coordinating an engine/rig project (the QA300/Turbine Rig project) that had particularly aggressive milestones and pressures from an external client. In an attempt to expedite certain tasks, Michael had engine/rig priorities in favour of the QA300. The only problem was he had obtained these job priorities without having specifically discussed this with the ECTR group manager (Frank). Prior to one of the intergroup meetings, Frank had made it clear in a one-on-one meeting with Michael that he hadn't appreciated his actions, and that future issues related to job priorities and resources needed to be discussed up-front with him first. During the inter-group meeting, Frank and Michael had avoided eye contact with one another. Both participated in the usual intermeshing of technical discussions and good-natured cajoling with the other members as the various items on the status list. But when Gerry called out "QA300/Turbine Rig?", Michael's normally expressive arms remained crossed as he started discussing the project's first-run milestones:

Michael: “...in reality the target is for mid-April, so it's important we complete all things...”

Frank's usually very expressive arms also remained crossed as he interrupts:

Frank (a bit impatient): "Yes, yes..."

Grant, the most senior member in the ECTR group, who has been working closely with Michael, then interjects in a neutral tone:

Grant: "Have we placed the order for the orifice plates?"

Frank (in a somewhat abrupt tone): "No. It's still in the design phase. (Then looking and speaking to Michael) The zinker plate costs 16,000 dollars if we go outside, but will cost a lot less if we do it inside...except that the surface finish requirements are real high..."

The tension between Frank and Michael is easily noticeable across their facial expressions and tightly crossed arms. Grant now interjects in an empathetic tone as he directs his question to Michael:

Grant: "Why is that?"

Frank (jumps in, still being abrupt): "Ya, why is that?"

Michael: "In the norms?"

Frank (somewhat less abrupt): "Ya...and when we were looking at that with Dan, I forget the numbers he was giving me, but he was saying..."

Grant interjects once more with an empathic tone, this time towards Frank:

Grant: "Using a grinder?"

Frank (now visibly more relaxed): "Ya, using a grinder...we'd need a bearing surface finish." 
Michael (showing empathy): "Holy cow!"

Although Frank's tone is now more conciliatory, both Frank and Michael's arms have remained crossed and immobile. There has been no sketching or showing of drawings during the technical discussion in regards to the 'zinker' plate; nor have they updated their respective status lists. But Frank's change in voice tone acts as a cue for others to cajole him:

Frank: "I was speaking to Joe about the CATIA plan..."

Richard (an EOD member who knows Frank quite well - says with a mischievous look): "Ya well, that's what you say...but the truth is he didn't want to speak to you in the first place."

The room explodes in laughter, including Michael.

Frank (trying to control his own laughter): "No. He was ready to speak to me about the frequencies..."

Richard (joking): “Ah, just send him to Poland and that'll solve that..."

Frank (biting his lip, and now trying to sound more serious): "He wanted to speak to me about the frequency spikes we saw last December...".

Tensions had risen and then subsided somewhat, almost like a therapeutic need to get it off their collective chests; and then partially healed or dampened across inter-group member involvement to bring about self-introspection across humour. In a later ad hoc interview that day, Frank tried to put things in perspective by saying, "Sometimes Michael can be a tad zealous in his pursuit to meet milestones...This is the only project he's coordinating, so he has lots of time to focus all his energies on it. He's gradually understanding that I've got 20 or more of these projects that require my group's services and support...He's young and still learning so that's allright." At the opening of the subsequent intergroup meeting, I found Frank slapping Michael's back in an affectionate manner, as they mischievously needled one another about resource issues. During the QA300 status discussion, Michael had taken out a 2-D drawing and was actively remodifying it to explain a specific problem pertaining to a turbine inlet duct that needed to be modified. Both Frank and Grant leaned over Michael's sketch and participated in modifying it as they made their own successive contributions to it. At the close of the discussion pertaining to the QA300, Michael, Grant and Frank had also modified their respective status lists.

A second high tension event involved a generic Request for Test (RT) form intended to be used by EOD, ECRT and the rest of the Engineering specialist community. This form, unilaterally initiated by Michael, attempted to identify all the steps involved in the preparation and actual running of a new test rig/engine using assumptions that resulted in the generic form underestimating actual project development times. Upon showing his 'strawman' version in an ad hoc meeting, Lloyd (the ECTR group leader) had initially misinterpreted Michael's draft version as a 'fait accompli'. Lloyd, who at first refused to look at Michael's draft generic form, began explaining in a somewhat brusque tone how he felt it was unrealistic to try and account for all the delays that typically occur throughout the development of an engine/test rig. But Michael, across patient explanation, had eventually convinced Lloyd that he was actually looking for 
Lloyd's input to try and improve the generic form, and then jointly see if it could in fact serve as a useful guide for creating specific RT's. Lloyd, seemingly more at ease, then began to look over the form (actively traversing it with his fingers) and proceeded to identify features that needed to be added or improved. In the subsequent EOD/ECTR inter-group meeting, Michael showed Lloyd the modifications he had made to the form according to Lloyd's earlier request. While discussing the form, Michael and Lloyd's fingers simultaneously traversed and pointed to various features of the newly modified form. Lloyd, visibly satisfied, viewed himself as a coowner and co-constructor of the generic RT form, as opposed to being subservient to it.

\section{ANALYSIS}

As previously mentioned in our methodology concerning the data analysis, certain phenomena, as a result of repeat occurrences, were retained; while further readings from the literature in regards to the phenomena repeatedly observed were brought into play to help us refine certain a priori categories and themes.

Our observed data clearly shows that different types of mediums can be used in helping to transmit perspectives within individual interactions that go beyond verbal articulation such as the use of agenda sheets, active sketching from scratch, sketching to modify existing drawings and the use of existing schematic drawings or documents themselves. Some of these 'objects' in their static forms such as the existing schematic drawings and documents could be classified as repositories as defined by Star and Griesemer (1989). And although authors such as Bødker (1998) and Lee (2007) acknowledge the activity or mediation that occurs around most of these 'objects', they are nevertheless viewed as either static representations or at best, punctuated 'snapshots'. Yet in most case, all of the listed 'objects' are usually accompanied with some form of visible action on the part of actors, and that it is during the dynamic yet transient modifications of these 'objects' by these very same actions that perspectives are both given and taken. For example, agenda sheets are actively modified across handwriting, as discussions advance from one item and/or topic to the next. And in conjunction to this dynamic reconstruction of the 'object' are the updating of everyone's own sense and perspective of the topic at hand - i.e. we are looking at both imaginary/mental as well as physical de-constructions and re-constructions occurring in tandem. In this sense, we concur with Suchman (2009) when she speaks of the agenda (as a form of plan) as an evolving artefact emerging from purposeful action (which she coins as situated action). Her use of the term action implies not only physical movement but also more reflexive components such as language and dialogue.

Another example such as the active process of sketching and re-sketching diagrams or representations is in a similar way much more meaningful across its dynamic construction and re-construction at the hands of participating actors then simply looking at the end-resultant sketch or construct. For example, Mark, a senior member of the EOD group, explains:

"It's as if you're constructing it - not concretely in mechanical terms, since it's more in a 'virtual' sense, but it's a lot more than just words. For example when I say 'We got to change this' - if you haven't seen it then you're wondering 'Change what?'...So by making a drawing I feel it makes the idea in your head come out for everyone to see - and have everyone better understand or feel your own experience...And that's how people can then say to you 'Ah that's what you 
meant. Well, in that case, no I don't think that's feasible...or ya, I think that can be done."”

And as Mark further adds, if the same explanatory words were used in the absence of specific motions and line drawing movements (e.g. the portraying of gas flows within a combustion chamber), one would have a less clear sense or understanding of the phenomena being articulated.

In all of these cases, we are looking at physical boundary objects being continually constructed and re-constructed by the subject-actors in a manner similar to Figure 1. We are essentially looking at 'artefacts as phenomena' as opposed to static pre-existing objects. Hence, we can speak of boundary (re-) constructions as proposed in our a priori framework (Figure 1). Even existing drawings without any visible line markings or modifications added to them, are typically accompanied by some form of finger or arm movements across various features and physical phenomena an actor wishes to bring a mental attention to (e.g. gas flows, stress distributions, hole diameters, etc.). This rejoins Weick's (1995) sense-making, in that this creates new mental bracketings necessary for constructing new mental representations within the minds of the various interacting members.

Yet, there is at least one element that was ignored in our initial framework (Figure 1) which requires further examination. A hint of this is provided to us by Latour's (1993) concept of hybridization of categories (in this case, the subject vs the object) - a hybridization involving an interpenetration or 'alloying' of one category into another. Is this what happens in 'real life'? In both the case of the agenda sheet and the sketching of drawings, there were various degrees of gestures, inscriptions, mapping, various forms of record keeping and the like that was used. Goodwin (2003, p.20) speaks of the "symbiotic" relationship between gestures and their objects, whereby the gesture's objects are integral components of the gesture itself. On the other hand, the actor is also integrally part of the gesture. It becomes somewhat tricky to define the clear cut boundaries between the bodies involved in the gesturing. Here, we are reminded of Glasersfeld's (2002, p.90-91) words: "To grasp as a unit what was just presented is to cut it out of the continuous flow...Focused attention picks a chunk of experience, isolates it from what came before and from what follows, and treats it as a closed entity." Not only are the contents of the bodies changing with time (in terms of the changing form of the artefact as well as the increasing comprehension achieved by the subject), but the boundaries themselves seem to shift or become blurred. The integral whole (of gesture, actor and object) becomes more easily understood as a phenomenon. Another example of this shifting nature of the subject-object boundaries can be found in Goodwin's (2004) description of technology intensive medicine, whereby she describes the transitions of patient anaesthetic states, "involving the radical reconfiguration of their capacity for action; specifically, for the sustenance of their own life support. Over the course of an anaesthesia, agency involved in the maintenance of vital bodily functions are progressively delegated from the patient as an autonomously embodied entity to an intricately interconnected sociomaterial assemblage and then back again" (cited in Suchman, 2009, p.263-264). Again, we are in front of a phenomenon made up of changing bodies (both in terms of contents and boundaries). Along these lines, Barad (2007) proposes an alternative onto-epistemology which she calls agential realism. Reality is viewed as a collection of phenomena involving the intraaction between agencies of observation and 'objects' (where both involve shifting boundaries or 'cuts'). These boundaries depend on context, points of views and observation apparatus configurations at hand. Observation apparatuses in themselves can involve both human and non- 
human bodily arrangements, which shift and intra-act with one another as phenomena. "Whereas the construct of interaction suggests two entities, given in advance, that come together and engage in some kind of exchange, intra-action underscores the sense in which subjects and objects emerge through their encounters with each other" (cited in Suchman, 2009, p.267). This processual ontology, in essence, repeats certain key aspects of Latour's actor network theory, in that knowledge as material practice emerges through the creation of networks (or apparatuses) which continually weave together, and hybridize, human and non-human elements (Blok and Jensen, 2011: 62). Orlikowski (2007, p.1437) elegantly summarizes this material-human intraaction as a socio-material entanglement, whereby "there is no social that is not also material, and no material that is not also social". Orlikowski's (2007, p.1438) socio-material entanglement is, for all intents and purposes, the same as Barad's (2007) agential realism: it is a "constitutive entanglement" which "departs from that of mutual or reciprocal interaction". Mutual or reciprocal interactions "presume the influence of distinct interacting entities on each other, but presuppose some a priori independence of these entities from each other...In contrast, the notion of constitutive entanglement presumes that there are no independently existing entities with inherent characteristics (citing Barad, 2003, p.816). Humans are constituted through relations of materiality — bodies, clothes, food, devices, tools, which, in turn, are produced through human practices".

\section{When Boundary Constructions Cease to be Effective: Coercion}

There were two instances where a given boundary construction process had either ceased to function or was initially having difficulty in fulfilling this desired role. In the first, sketching from scratch, references to or modifications to drawings, as well as reference to the status list had literally stopped during moments of antagonistic tensions between two inter-group members (Frank and Michael). Sense-making, had also temporarily dropped to moments of non-exchange and coercion, whereby Frank and Michael's respective perspectives had entrenched themselves into 'self-crediting', all the while trying to mutually 'dis-credit' the other's perspectives. Fortunately, this tension was only temporary, and the three types of boundary constructions were eventually re-enacted for the QA300 at the subsequent inter-group meeting. In the case of the generic RT form, initial misunderstandings had made Lloyd momentarily assume that Michael was out to coerce, therefore preventing the possibility of co-constructing an effective boundary construction. Misunderstandings were worked out, leading to positive dialogue. This energized the RT form to become an effective co-construction between the two actors.

The bi-weekly meeting setting provided a forum in which inter-group member interactions built and maintained interpersonal ties, and where people felt at ease to share both technical and personal-social experiences. Such a forum or location is often referred to as $b a$ by Nonaka and Konno (1998). Although we did not analyze the issue of power relations in any real depth, our first impression was that intra-group dynamics within both the EOD and ECTR groups seemed much more in line with Follett's $(1924,101)$ concept of coactive power or "power with" than coercive power (or "power over"). In general, differing ideas were voiced without fear of retributions or ridicule. It would be naive to conclude that there were no power asymmetries within and between the groups. For example, one would need to examine the possible influence of knowledge content or rank between members. There is also the possible question of relative institutional positions or 'hierarchies' of both groups within the organization. On this latter question, the formal sense of EOD/ECTR group relationship is that of client/supplier (see section 3.1), whereby one may be tempted to assume that a porterian analysis could be of use. Yet, the 
informal nature of the interactions existing between both groups also showed a heavy collaborative 'flavour' between both groups. Or as Jeremy (from the EOD group) and Jon (from the ECTR group) explained on separate occasions:

Jeremy: "We're pretty close with Frank's (ECTR) group. We could easily be sitting together instead of being in separate buildings. I feel really comfortable with that group."

Jon: "There's a real sense of gratification and pride rubbing shoulders with these guys (EOD group). They make me evolve and improve myself... They really take the time to explain things to me."

Ideas were challenged and debated on both sides before arriving to an "equivalent meaning" (Weick, 2009, p.145). The shaping and influence over the construction of reality was never onesided; or as Weick (2009) puts it, meaning survived, more often than not, as a result of equally weighted votes.

Yet, sense-giving (as opposed to sensemaking) was also present on occasion where either a knowledgeable member wanted to transmit his views in a pedagogical manner so as to teach/mentor a younger or inexperienced member; or where one of the managers wanted to describe the issues and context of a given situation (again, with the aim of guiding), via the use of narratives and story-telling. Such sense-giving did not overpower the general tone of freedom of expression and debate; for as Weick (2009, p.161) explains, "in situations with large power differentials, people with more power have the freedom to define reality, which means they need to spend less time trying to understand how reality is constructed", and as such, where there is the danger of "power makes people stupid" (Flyvberg 1998, p.37 and p.229). The fact that we indeed observed relational engagement (Tsoukas, 2007), whereby we sensed that members were actively trying to take in each other's views, would tend to confirm the lack of any coercive power at play.

\section{The Need for a Psychological Safety}

According to Barad (2007), we live in an indeterminate world, yet as Weick (2009, p.199) points out, "an indeterminate world is not a random world. Instead, it is loosely coupled, amenable to multiple interpretations, malleable to action, and contingent." Throughout the complexity of enactment and agency, boundaries between humans and non-humans are not given but constructed (Barad, 2007). "Boundaries are necessary for the creation of meaning, and are therefore never innocent... Responsibility on this view is met neither through control nor abdication but in ongoing practical, critical, and generative acts of engagement" (Suchman, 2009, p.285-286). Such an engagement involves perspectives to be aired and exchanged across verbal articulation and non-verbal body-movements (the latter being especially present within dynamic acts of boundary constructions between interacting individuals), whereby there is a continuous re-visiting and re-adjustments of ideas and concepts. Yet for this to happen, individuals must first feel secure to interact with one another within an environment of confidence or trust (Edmonson, 1999). This is primordial for truly reciprocal dialogical interactions to occur whereby individuals feel comfortable in expressing themselves on the one hand, and to mentally 'step into another's shoes' on the other hand (Enriquez, 1992). Hence, it becomes important for management to nurture mutual trust, mutual respect, empathy, and care which in turn provides a psychological "safety net", whereby people feel comfortable in learning 
and trying new ideas. Frank, the ECTR manager, spoke of a "parental" approach which requires a judicious balance between encouraging a gradual transition towards autonomy as members gain confidence and knowledge on the one hand, and always being present in the background so as to provide needed support when members face particularly daunting issues and problems on the other hand. The term 'parental' should not be misconstrued with the term 'paternalistic' (as referenced by various authors such as Crener and Monteil (1981), etc.) whereby management does not allow members to take the initiative towards making their own decisions, thereby severely limiting autonomy. In Frank's parental approach, we are reminded of Bateson (1978, p.498):

"During the period when the acrobat is learning to move his arms in an appropriate way, it is necessary to have a safety net under him, i.e., precisely to give him the freedom to fall off the wire. Freedom and flexibility in regards to the most basic variables may be necessary during the process of learning..."

Within such an environment, mistakes or errors are not condemned but rather seen as opportunities to learn, improve oneself and improve the group collectively across the sharing of 'lessons learned'. Such a psychological "safety net" provides a shared belief amongst the members that the group "is safe for interpersonal risk-taking" (Edmondson, 1999, p. 351). The lack of a psychological 'safety net' can, on the other hand, prevent not only individual risktaking which is necessary in exploring new venues of knowledge, but also discourage the learning and sharing of knowledge amongst various members. As such, members can often fall into an individualistic survival mode, whereby, in an attempt to compensate for the absence of a general shared feeling of psychological safety, have recourse towards various psychological defences leading towards a "relational risk" in which members hold back critical knowledge from one another (Bogenrieder and Nooteboom, 2004, p.293-294).

\section{SUMMARY AND CONCLUSIONS}

Building upon current perspectives of boundary objects, this paper first proposes the alternative concept of boundary (re-)constructions. Our initial framework depicted individual subjects as being able to shape objects across enactment phenomena just as in turn objects shape subjects' interpretations and experiences. Our basic research question was to then inquire as to what conditions may contribute towards productive human/object interactions leading towards effective knowledge sharing. Our results, at first glance, seemed to confirm human/object interactions as a mutual shaping process. Yet further analysis made us question the residual duality within this initial concept. Onto-epistemological insights from Latour's (1993) hybridized categories and Barad's (2007) and Orlikowski's (2007) equivalent concepts of agential realism and socio-material entanglement allow us to reframe boundary (re)constructions as intra-actions (as opposed to inter-actions) between humans and objects, which involve shifting boundaries or 'cuts' depending on the context, points of views and configurations at hand. Hence, the effective knowledge sharing observed is due to productive intra-actions (as opposed to inter-actions).

In turn, certain conditions which we felt either supported or may even have enabled these productive intra-actions, include, but are certainly not limited to, the relative absence of coercive power, and the presence of psychological safety. We can reword this by saying that boundary 
(re-)constructions help bring sense and meaning to perspectives being given and taken within dialogical interactions. The active role of individuals in boundary (re-) constructions implies accountable and responsible engagements. Such engagements require confidence between participating parties, which in turn, requires management's implication in providing a psychological safety net within the workplace.

This single case study prevents us from generalising our findings across the entire firm in question; and by extension, any manner of external validity outside of the firm's context. Additional workgroups/teams within the firm need to be evaluated; while similar studies in other institutions within the knowledge economy are envisaged.

\section{REFERENCES}

Barad, K. (2007). Meeting the Universe Halfway: Quantum Physics and the Entanglement of Matter and Meaning, Durham NC: Duke University Press.

Bateson, G. (1978). Steps to an Ecology of Mind, London: Paladin.

Beaulieu, A., A. Scharnhorst and P. Wouters. (2007). Not another case study, Science, Technology and Human Values, 32(6), 672-692.

Bechky, B.A. (2003). Sharing meaning across occupational communities: The transformation of understanding on a production floor, Organization Science, 14(3), 312-330.

Berger, P.L. and T. Luckmann. (1966). The Social Construction of Reality, Garden City, NY: Anchor Books.

Blok, A. and T.B. Jensen. (2011). Bruno Latour: Hybrid Thoughts in a Hybrid World. London, UK: Routledge, Taylor and Francis Group.

Bødker, S. (1998). Understanding representation in design, Human-Computer Interaction 13(2), 107-125.

Bogenrieder, I. and B. Nooteboom. (2004). Learning groups: What types are there? A theoretical analysis and an empirical study in a consultancy firm, Organization Studies, 25(2), 287-313.

Carlile, P.R. (2002). A pragmatic view of knowledge and boundaries: Boundary objects in new product development, Organization Science, 13(4), 442-455.

Carlile, P.R. (1997). Understanding knowledge transformation in product development: Making knowledge manifest through boundary objects, Ph.D. diss., University of Michigan.

Crener, M. and B. Monteil. (1981). Principes de Management, Sillery (Québec): Les Presses de l’Université du Québec.

Cresswell, J.W. (1998). Qualitative Inquiry and Research: Choosing Among Five Traditions, Thousand Oaks, CA: Sage Publications. 
Cuche, D. (2004). La notion de culture dans les sciences sociales, $3^{\text {rd }}$ Ed., Paris: Repères.

Edmondson, A. (1999). Psychological safety and learning behavior in work teams, Administrative Quarterly, 44(2), 350-383.

Eisenhardt, K.M. (1989). Building theory from case study research, Academy of Management Review 14(4), 532-550.

Enriquez, E. (1992). L’Organisation en analyse, Paris: Presses Universitaires de France.

Fahey, L. and L. Prusak. (1998). The eleven deadliest sins of knowledge management, California Management Review, 40(3), 265-276.

Feldman, M.S., A.M. Khademian, H. Ingram, and A.S. Schneider. (2006). Ways of knowing and inclusive management practices, Public Administration Review, 66, 89-99.

Flyvberg, B. (1998). Rationality and Power: Democracy in Practice, Chicago, Il: University of Chicago Press.

Follett, M.P. (1924). Creative Experience, New York: Longman, Green.

Glasersfeld, E. von. (2002). Radical Constructivism: A Way of Knowing and Learning, London: RoutledgeFalmer.

Goodwinn, C. (2003). The body in action. In J. Coupland and R. Gwyn (Eds), Discourse, the Body and Identity, (pp. 19-42), New York: Palmgrave/MacMillan.

Goodwinn, D. (2004). Acting in anaesthesia: Agency, participation, and legitimation, Ph.D. diss., Lancaster University.

James, W. (1955). Pragmatism, Cleveland/New York: Meridian Books (first published in 1907).

Latour, B. (1993). We Have Never Been Modern, Cambridge, MA.: Harvard University Press.

Lee, C.P. (2007). Boundary negotiating artifacts: Unbinding the routine of boundary objects and embracing chaos in collaborative work, Computer Supported Cooperative Work, 16(3), 307-339.

Lincoln, Y.S. and E.G. Guba. (1985). Naturalistic Enquiry, Newbury Park, CA: Sage Publications.

Lutters, W.G. (2001). Supporting reuse: IT and the role of archival boundary objects in collaborative problem solving, Ph.D. diss., University of California.

Mead, G.H. (1934). Mind, Self and Society, Chicago: University of Chicago Press. 
Morgan, G. (1997). Images of Organization, 2nd edition, Thousand Oaks, CA: Sage Publications.

Orlikowski, W.J. (2007). Sociomaterial practices: Exploring technology at work. Organization Studies, 28(9), 1435-1448.

Prosser, J. (1995). An ethnographic case study approach to studying the process of child abuse investigations in the United Kingdom, Institute for Psychological Therapies, 7(3), 32-49.

Rosaldo, R. (1989). Culture and Truth. The Remaking of Social Analysis, Boston: Beacon Press.

Schober, M. (1998) Different kinds of conversational perspective-taking, Social and Cognitive Approaches to Interpersonal Communications, Manwah, N.J.: Lawrence Erbaum Associates.

Schwartzman, H.B. (1993). Ethnography in Organizations, Newbury Park, CA: Sage Publications.

Spradley, J.P. (1980). Participant Observation, New York: Rinehart and Winston.

Star, S.L. and J.R. Griesemer. (1989). Institutional ecology, 'translations' and boundary objects: Amateurs and professionals in Berkeley's Museum of Vertebrate Zoology, Social Studies of Science, 19(3), 387-420.

Suchman, L.A. (2009). Human-Machine Reconfigurations: Plans and Situated Actions, $2^{\text {nd }}$ Edition, Cambridge UK: Cambridge University Press.

Tsoukas, H. (2009). A dialogical approach to the creation of new knowledge in organizations. Organization Science, 20(6), 941-957.

Weick, K.E. (1979). The Social Psychology of Organizing, $2^{\text {nd }}$ Edition, Reading, MA: AddisonWesley Publishing Co.

Weick, K.E. (1995). Sensemaking in Organizations, Thousand Oaks, CA: Sage Publications.

Weick, K.E. (2001). Managing the Unexpected. Assuring High Performance in an Age of Complexity, San Francisco, CA: Jossey-Bass.

Weick, K.E. (2009). Making Sense of the Organization (Volume 2): The Impermanent Organization, West Sussex UK: John Wiley and Sons Ltd.

Wenger, E. (1998). Communities of Practice: Learning, Meaning and Identity, Cambridge, UK.: Cambridge University Press.

Whitehead, A.N. (1954). Dialogues of Alfred North Whitehead, Boston, MA: Little, Brown. Yin, R.K. (2003). Case Study Research: Design and Method, Thousand Oaks, CA: Sage Publications. 